\title{
Population genetic study of diabetes and diabetic retinopathy among Egyptians
}

\author{
El Ela MHA ${ }^{1}$, Azeem AAA ${ }^{2}$, Elbastawisy $\mathrm{HI}^{1}$, Osman $\mathrm{ZM}^{3}$ \\ Department of Public Health, Research Institute of Ophthalmology, Cairo, Egypt. manalabuelela@yahoo.com
}

\begin{abstract}
Objectives: To clarify the population genetic background of diabetes mellitus among Egyptians and its effect on developing diabetic retinopathy (DR).

Background: Genes play an important role in the development of diabetes mellitus.

Methods: A statistical study was carried on 214 patients with diabetes mellitus after clinical genetic evaluation including medical and family history, family pedigree analysis, and determination of blood sugar, cholesterol and triglycerides levels. Ophthalmic examination was done to detect diabetic retinopathy.

Results: Family history of diabetes was higher in type I while parental consanguinity was higher in type II. Type I diabetics had positive familial aggregation with sharp falling in frequency of affection from the first to the second to the third degree relatives. Type II diabetes is generally a disease of multifactorial inheritance and AD inheritance in part of pedigrees; however AR inheritance could not be excluded. Family history of DR was higher among diabetic patients with DR than in patients without retinopathy $(p<0.05)$. Female gender, type I diabetes, duration of diabetes, triglycerides and positive family history of diabetic retinopathy were predictive risk factors for DR. Conclusion: Genetic factors play an important role in various forms of DM, however the inheritance is complex. Although most cases of DM are multifactorial disorders, monogenic forms have been also identified. Family history is an important risk factor for the development of DR. Molecular studies are recommended to detect which of the implicated genes are responsible for the development of DR among diabetic Egyptians (Tab. 4, Fig. 1, Ref. 18). Full Text in PDF www.elis.sk.

Key words: genetics, diabetes, diabetic retinopathy.
\end{abstract}

Diabetes mellitus continues to be a major source of morbidity and mortality among working-age adults (1). The prevalence of diabetes for all age-groups worldwide was estimated to be $2.8 \%$ in the year 2000 and $4.4 \%$ in 2030 . The total number of people with diabetes is projected to rise from 171 million in the year 2000 to 366 million in 2030 . The greatest relative increase will occur in India, the Middle Eastern Crescent and sub-Saharan Africa (2). The prevalence of diabetes in the Egyptian population $\geq 20$ years of age was found to be $9.3 \%$ (3).

Genes play an important role in the development of diabetes mellitus. Putative susceptibility genes could be the key to the development of diabetes. The pathogenetic sequence leading to the selective autoimmune destruction of islet beta-cells and development of type 1 diabetes involves genetic factors, environmental factors, immune regulation and chemical mediators. Type 2 diabetes is often considered a multifactorial disorder with multiple genes located on different chromosomes. This is further complicated by numerous environmental factors which also contribute to the

${ }^{1}$ Department of Public Health, Research Institute of Ophthalmology, Cairo, ${ }^{2}$ Department of Ophthalmic Genetics, Research Institute of Ophthalmology, Cairo, and ${ }^{3}$ Department of Ophthalmology, Research Institute of Ophthalmology, Cairo

Address for correspondence: Manal H. Abu El Ela, MD, Dept of Public Health, Research Institute of Ophthalmology, 19 Gaafer Street, Haram, Cairo, Egypt.

Phone: +2035835906 clinical manifestations of the disorder in genetically predisposed persons (4). The microvascular complications of diabetes including diabetic retinopathy account for a major proportion of diseaseassociated morbidity. Although blood sugar control contributes to susceptibility for diabetic complications, some people with strict control develop these complications, whereas others with poor control remain complication free. This suggests a genetic contribution to the disease development. Although many genes and proteins of vascular growth have been studied in association with diabetic retinopathy, no definitive major predisposing genes or functional consequences of genetic variants have been identified for microvascular complications of the disease (1).-

The aim of this study was to clarify genetic factors among Egyptian diabetic patients, and their effect in the development of diabetic retinopathy.

\section{Methods}

A cross-sectional epidemiological, questionnaire-based study was carried out over a period of one year. The target sample size for the study was 214 patients from 212 families with diabetes mellitus who were referred from the Medical and Ophthalmic clinics at the Research Institute of Ophthalmology to the Ophthalmic Genetics clinic. Collected information included demographic data (age and gender, age at the diagnosis, mean duration of the disease) and test results (blood sugar, total cholesterol and triglycerides levels). All 
patients underwent clinical genetic evaluation including medical and family history and family pedigree analysis to investigate parental consanguinity, and the intrafamilial clustering of type I and type II diabetes. Ophthalmic examination was done for all patients to detect diabetic retinopathy, its type and degree using biomicroscopy and fluorescein angiography in needed cases.

A statistical study was performed aiming for the detection of the genetic model of type II diabetes mellitus.

For autosomal dominant inheritance, we used the hypothesis given by Neel and Schull (5).

$\mathrm{X}^{2}=\sum \frac{(0-E)}{E}$

$\mathrm{O}=$ Observed number

$\mathrm{E}=$ Expected number

$\mathrm{X}^{2}$ to be significant should not exceed 3.841 with one degree of freedom.

For autosomal recessive inheritance, Fisher's equation (6) for single incomplete ascertainment was used.

$P=\frac{R-N}{T-N}$

Which has a $S . E=\sqrt{\frac{p q}{T-N}}$

$\mathrm{P}=$ Theoretical proportion i.e. 0.25

$\mathrm{R}=$ Number of affected individuals in all sibships, under analysis.

$\mathrm{N}=$ Number of sibships under analysis.

$\mathrm{T}=$ Total number of individuals in all sibships under analysis.

$\mathrm{q}=1-\mathrm{P}$

To be consistent with autosomal recessive «P» should be near to 0.25

For X-linked inheritance, inspection of all pedigrees was done to prove the presence or absence of the characteristics of both X-linked dominant and X-linked recessive inheritance. For multifactorial inheritance, certain criteria were searched for (7). They comprised the frequency of the disease among relatives and the recurrence risk for relatives of patients of less susceptible sex (males). We studied the effect of different risk factors in the development of diabetic retinopathy using linear regression analysis. The family history of diabetic retinopathy among diabetic cases with and without DR was also compared.

Linear regression analyses were performed to test the possibility of association between different risk factors and the development of diabetic retinopathy. All statistical analyses were con-

Tab. 1. Family history and parental consanguinity in diabetic patients.

\begin{tabular}{lrrrrrr}
\hline Variable & \multicolumn{5}{c}{ Diabetic cases } \\
\cline { 2 - 7 } & $\begin{array}{c}\text { Type I } \\
\mathrm{n}(\%)\end{array}$ & $\begin{array}{c}\text { Type II } \\
\mathrm{n}(\%)\end{array}$ & $\begin{array}{r}\text { Total } \\
\mathrm{n}(\%)\end{array}$ \\
\hline Family history & 15 & 93.8 & 178 & 89.9 & 193 & 90.2 \\
$\quad \begin{array}{l}\text { positive } \\
\text { negative }\end{array}$ & 1 & 6.2 & 20 & 10.1 & 21 & 9.8 \\
\hline Parental consanguinity & & & & & & \\
$\quad$ positive & 3 & 18.7 & 55 & 27.8 & 58 & 27.1 \\
$\quad$ negative & 13 & 81.3 & 143 & 72.2 & 156 & 72.9 \\
\hline
\end{tabular}

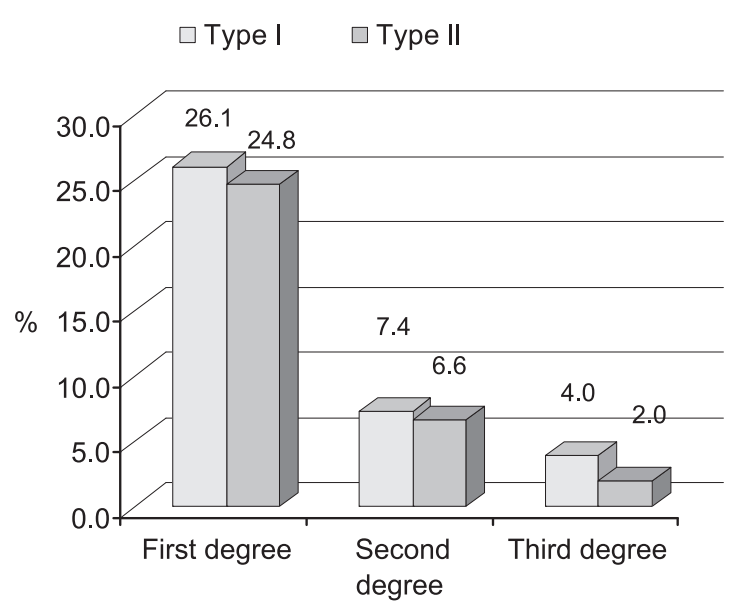

Fig. 1. Frequency of diabetes among relatives of our probands.

ducted using SPSS software (SPSS software version 10). $\mathrm{p}$ value of $<0.05$ was considered statistically significant.

\section{Results}

Patients were 65 males (30.4\%) and 149 females (69.6\%) and their ages ranged between 15 to 75 years. One hundred ninety eight patients $(92.5 \%)$ were diagnosed as diabetics type II and 16 patients $(7.5 \%)$ as diabetics type I. Family history of diabetes was higher in type I than in type II while parental consanguinity was higher in type II than in type I (Tab. 1). Positive familial aggregation was present in both type I and type II diabetes with sharp falling in the frequency of disease from the first to the second to the third degree relatives (Fig. 1). Only one parent was affected in $50 \%$ of patients of diabetes type I and $41.4 \%$ of patients of diabetes type II. Two parents were affected in $6.3 \%$ and $10.1 \%$ of them. Siblings were affected in $50 \%$ of patients of diabetes type I, and $60.1 \%$ of patients of diabetes type II. According to Neel and Schull (5) we applied $\chi^{2}$ test on the offspring of affected parents of type II diabetes probands. Out of total of 666 offspring of affected parents, 324 cases were similarly affected while the expected number of normal or affected should be around $333(50 \%) \cdot \chi^{2}=$ 0.486; suggested autosomal dominant inheritance and dominant major gene might influence the genesis of type II diabetes mellitus among Egyptians.

According to Fisher's equation (6), p was $=0.32 \pm 2(0.0164)$; and this value is more than expected for autosomal recessive inheritance i.e. 0.25 but it is not far away from it so that autosomal recessive inheritance also could not be excluded among Egyptians. Inspection of family pedigrees of affected families showed no consistent pattern suggestive of X-linked inheritance. Twentyone affected males had non-affected daughters excluding the possibility of X-linked dominant inheritance. Furthermore, there were sixty-three cases of direct male to male transmission of both type I and type II diabetes which was inconsistent with both X-linked recessive or dominant inheritance.

Figure 1 showed that there was a sharp falling in the frequency of affected relatives from first degree relatives to second degree 
Tab. 2. Frequency of affected individuals among relatives of affected males and females with type II diabetes.

\begin{tabular}{lcc}
\hline Probands & \multicolumn{2}{c}{ Affected } \\
\cline { 2 - 3 } & $\mathrm{n} /$ total & $\%$ \\
\hline Males & $228 / 2590$ & $8.8 \%$ \\
Females & $484 / 5976$ & $8.1 \%$ \\
\hline
\end{tabular}

Tab. 3. Family history of DR among diabetic cases with \& without DR.

\begin{tabular}{lcccc}
\hline DR State & \multicolumn{3}{c}{ Family history of DR } \\
\cline { 2 - 5 } & \multicolumn{2}{c}{ Positive } & \multicolumn{2}{c}{ Negative } \\
\hline & $\mathrm{n} /$ total & $\%$ & $\mathrm{n} /$ total & $\%$ \\
positive $(46.7 \%)$ & $36 / 100$ & $(36.0)$ & $64 / 100$ & $(64.0)$ \\
negative (53.3\%) & $15 / 114$ & $(13.2)$ & $99 / 114$ & $(86.8)$ \\
\hline
\end{tabular}

Tab. 4. Linear regression analysis of factors associated with DR.

\begin{tabular}{lccc}
\hline Variable & $\begin{array}{c}\text { Standardized } \\
\text { Coefficients }\end{array}$ & $\mathrm{t}$ & $\mathrm{p}$-value \\
\hline Female gender & 0.245 & 2.467 & 0.016 \\
Type I diabetes & 0.222 & 2.187 & 0.032 \\
Duration of diabetes & 0.334 & 3.243 & 0.002 \\
Triglycerides & 0.28 & 2.804 & 0.007 \\
Positive family history of DR & 0.238 & 2.393 & 0.020 \\
\hline Variables not in the equation & & & \\
\hline Age & -0.136 & -1.149 & 0.255 \\
Control of diabetes & 0.016 & 0.153 & 0.879 \\
Total cholesterol level & -0.108 & -0.986 & 0.328 \\
\hline
\end{tabular}

relatives and from second to third degree relatives in type II diabetes. The frequency of affected individuals among relatives of diabetic male probands (less susceptible sex) was $(8.8 \%$ ) greater than the frequency of affected individuals among relatives of affected females $(8.1 \%)$ as shown in Table 2 . These criteria suggest the multifactorial type of inheritance.

Table 3 showed that $46.7 \%$ of diabetic patients had diabetic retinopathy, and the family history of DR was significantly higher among patients with DR than in diabetic patients without retinopathy $(p<0.05)$. Linear regression analysis in Table 4 indicated that female gender, type I diabetes, duration of diabetes, triglycerides and positive family history of diabetic retinopathy were predictive risk factors for diabetic retinopathy and $p$ values were 0.016 , $0.032,002,0.007$ and 0.02 , respectively while age, control of diabetes and total cholesterol level had no significant association with retinopathy ( $\mathrm{p}$ values were $0.26,0.88$ and 0.33 respectively).

\section{Discussion}

Diabetes mellitus (DM) in adults is a global health problem although its prevalence varies widely between different populations and the rate has generally increased worldwide (8). It is estimated that in 2025, Egypt may be among the ten leading countries in the world in terms of the number of people with diabetes (9). Our study showed that male to female ratio was $1: 2.3$. This coincides with a previous Egyptian study showing that the prevalence of diabetes was higher among female Egyptian patients than in males (10.9\% and $7.84 \%$, respectively) (10). Another Chinese study by Zhang et al (11) found that the incidence of DM was much higher in females than in males (40\% and $28 \%$ ). This study also showed that type
I to type II ratio was $1: 12.4$ while Abo Dahab and his colleagues (10) previously found that the prevalence of type $1 \mathrm{DM}$ comprised $1.64 \%$ vs $7.74 \%$ for Type 2 DM among Egyptian patients.

Comprehensive analysis of 212 family pedigrees proved that type II diabetes is generally a disease of multifactorial inheritance and autosomal dominant (AD) inheritance in part of pedigrees; however the autosomal recessive inheritance could not be excluded among Egyptian patients. X- linked dominant and recessive could be excluded in studied pedigrees of both types of diabetes. Type I diabetes had a positive familial aggregation with a sharp falling in the frequency of affection from the first to second to third degree relatives however we could not apply Neel and Schull and Fisher's equations $(5,6)$ on the family pedigrees of type I diabetes families as we needed larger samples of patients and their relatives to have reliable results. Ma et al in 2008 (12) had a similar study in china that included 715 Type II DM pedigrees and they concluded that there was a significant familial aggregation in Type II DM and the first-degree relatives of patients were high-risk populations. Mohan and his colleagues (13) found that $10.2 \%$ of Type II DM subjects had evidence of $\mathrm{AD}$ inheritance in India.

Various grades of diabetic retinopathy were diagnosed among $46.7 \%$ of our diabetic patients. This reasonably agrees with the prevalence identified in other parts of the world. In Brazil, in a study on 210 Caucasians cases with type II diabetes, the prevalence was $47 \%$ (14) while in Jordan, Ali-Till and his colleagues (15) documented the prevalence of $64.1 \%$ in their diabetic patients. A Pakistani study on 500 diabetic patients documented that $43 \%$ of them had diabetic retinopathy.

Linear regression analysis indicated that female gender, type I diabetes, duration of diabetes, triglycerides and positive family history of diabetic retinopathy were predictive risk factors for diabetic retinopathy and $p$ values were $0.016,0.032,0.002,0.007$ and 0.02 , respectively. At the same time, age, control of diabetes and total cholesterol level had no significant association with retinopathy ( $\mathrm{p}$ values were $0.26,0.88$ and 0.33 respectively) among Egyptian patients.

Many authors studied the risk factors of development of diabetic retinopathy among diabetic patients and each study documented different parameters; Elshafei et al (16) found that longer duration of diabetes and poor glycemic control were significantly associated with diabetic retinopathy. Chen et al (17) found that diabetic retinopathy was correlated with the duration of diabetes, age at onset of diabetes, type of diabetes treatment, and higher serum creatinine level. Several other factors including gender, age, residential area, control and family history of diabetes had no significant association with retinopathy.

Marshall et al (18) studied factors influencing the onset and progression of diabetic retinopathy in subjects with insulin-dependent diabetes mellitus in Denver and they confirmed that four factors were significantly associated with the etiology and the progression or regression of diabetic retinopathy: age, duration of diabetes, mean longitudinal GHb levels (all at $\mathrm{p}<0.01$ ), and diastolic blood pressure $(p<0.04)$. However, age was no longer significant when justified by duration of diabetes. The difference 
in the effects of risk factors in different races may be related to changes in genetic backgrounds between them.

In conclusion, there is a significant familial aggregation in both type II DM and type I DM. The first-degree relatives of diabetic patients are high-risk populations. Therefore long-term monitoring and early screening should be performed. Female gender, type I diabetes, duration of diabetes, triglycerides and positive family history of diabetes mellitus are important risk factors for the development of diabetic retinopathy in Egyptian diabetic patients. There is clearly a need to develop strategies to identify persons at risk of diabetic retinopathy in order to allow prevention and early intervention.

\section{References}

1. Patel S, Chen H, Tinkham NH, Zhang K. Genetic susceptibility of diabetic retinopathy. Curr Diab Rep 2008; 8 (4): 257-262.

2. Arya M. www.similima.com/pm105.htm (accessed 2010).

3. Herman WH, Aubert RE, Ali MA, Sous ES, Badran Ahmed A. Diabetes mellitus in Egypt: risk factors, prevalence and future burden. Eastern Mediterranean Health J 1997; 3 (1): 144-148.

4. Radha V, Vimaleswaran KS, Deepa R, Mohan V. The genetics of diabetes mellitus. Indian J Med Res 2003; 117: 225-238.

5. Neell JV and Schull WJ. Human Heredity, Chicago Univ. Press. 1954. Quoted from Emery A.E.H.: Methodology in medical genetics. EdinburgLondon-New York: Churchill Livingstone 1976; 35-36.

6. Fisher RA. The effect of methods of ascertainment upon the estimation of frequencies. Ann Eugen London 1943; 6: 13-25.

7. Emery AEH. Methodology in Medical Genetics. Edinburg-LondonNew York: Churchill Livingstone: 1976; 16-19, 35-60.

8. Chang C, Lu F, Yang YC, Wu JS, Wu TJ, Chen MS, Chuang LM, Tai TY. Epidemiologic study of type 2 diabetes in Taiwan. Diabetes Res Clin Pract 2000; 50 (Suppl 2): S49-59.
9. Herman W, Ali MA, Aubert R E, Engelgau MM, Kenny SJ, Gunter SW. Diabetes mellitus in Egypt : risk factors and prevalence. Diabetes Med 1995; 110: 201-203.

10. Abo Dahab LH, Moftah FM, Hassanein HA, El-Kady AF, Zeinab F, Deyab M, El-Sayed AA. Epidemiology of Diabetes Mellitus in Sohag Governorate. Assiut Med J 2000; 24 (1): 2000.

11. Zhang S, Yu L, Qiu H. Pedigree investigation of familial non-insulin dependent diabetes mellitus. Zhonghua Yi Xue Za Zhi 1996; 76 (6): 435-439.

12. Ma XJ, Jia WP, Hu C, Zhou J, Lu HJ, Zhang R, Wang CR, Wu SH, Xiang KS. Genetic characteristics of familial type 2 diabetes pedigrees: a preliminary analysis of 4468 persons from 715 pedigrees. Zhonghua Yi Xue Za Zhi 2008; 88 (36): 2541-2543.

13. Mohan V, Pranjali PP, Amutha A, Ganesan A, Datta M, Gayathri P. Prevalence and clinical profile of autosomal dominant type 2 diabetes from a diabetes centre in India. Prim Care Diabetes 2009; 3 (4): 233-238.

14. Santos KG, Tschiedel B, Schneider JR, Souto KE, Roisenberg I. Prevalence of retinopathy in Caucasians type 2 diabetic patients from the south of Brazil and relationship with clinical and metabolic factors. Braz J Med Biol Res 2005; 38 (2): 221-225.

15. Ali-Till, Al-Bdour MD, Ajlouni KM. Prevalence of blindness and visual impairment among Jordanian diabetics. Eur J Ophthalmol 2005; 15 (1): $62-68$.

16. Elshafei M, Gamra1 H, Khandekar R, Al Hashimi M, Pai A, Ahmed MF. Prevvalence and determinants of diabetic retinopathy among persons $\geq 40$ years of age with diabetes in Qatar: a community-based survey. Eur J Ophthalmol 2011; 21 (1): 39-47.

17. Chen MS, Kao CS, Chang CJ, Wu TJ, Fu CC, Chen CJ, Tai TY. Prevalence and risk factors of diabetic retinopathy among noninsulindependent diabetic subjects. Am J Ophthalmol 1992; 114 (6): 723-730.

18. Marshall G, Garg SK, Jackson WE, Holmes DL, Chase HP. Factors influencing the onset and progression of diabetic retinopathy in subjects with insulin-dependent diabetes mellitus. Ophthalmology 1993; 100 (8): 1133-1139. 